\title{
LA MORTALIDAD ANTES DE ENTRAR EN LA VIDA ACTIVA EN ESPAÑA \\ COMPARACIONES REGIONALES \\ E INTERNACIONALES, 1860-1960
}

XAVIER CUSSÓ y ROSER NICOLAU

Departamento de Economía e Historia Económica

Universidad Autónoma de Barcelona

\section{RESUMEN}

Este artículo analiza la evolución de las disparidades regionales de la mortalidad de los jóvenes españoles entre 1860 y 1960 . En primer lugar, muestra que las infecciones digestivas fueron la causa inmediata de la sobremortalidad española y la causa más importante también de sus variaciones regionales internas. En segundo lugar, considera el singular contexto ecológico de las regiones de la España húmeda como el factor decisivo para explicar las ventajas comparativas que en términos de salud y sobrevivencia alcanzaron aquellas regiones antes de finales del siglo XIx. Finalmente explica por qué a partir de entonces, con los descubrimientos de la microbiología, se estableció una nueva y más estrecha relación entre la renta y la mortalidad regionales.

\section{ABSTRACT}

In this work we analyse the changes in the regional distribution of mortality for young Spaniards between 1860 and 1960 . First we show that digestive infectious diseases were the immediate cause of excess mortality in Spain compared to Northern and Central European countries. These diseases were also the main factor in the regional differences of mortality in Spain. In our second point we single out the peculiar ecological setting of Atlantic Spanish regions as the most important factor for their comparative advantage in morbidity and mortality at the end of the nineteenth century, relative to the rest of Spain and also to some Northern European regions. In the last part we argue that it was the microbiological revolution that established the direct relation between the standard of living and regional mortality differences that characterise Spain in the twentieth century. 
Una de las características más sobresalientes de la población española durante la primera mitad del siglo xx fue la acusada sobremortalidad de los niños, en particular de uno a cuatro años de edad, en relación a los países del norte y centro de Europa. Esta sobremortalidad limitó significativamente las proporciones de sobrevivientes que alcanzaban la edad de entrada en actividad y las esperanzas de vida de las generaciones espanolas nacidas antes de mediados del siglo $\mathrm{xx}$.

Este hecho, aunque es bien conocido, ha recibido escasa atención por parte de los historiadores económicos españoles y el propósito de este artículo es despertar su interés por esta cuestión. En primer lugar se presentan las series de mortalidad de distintos países europeos y las interpretaciones tradicionales de las diferencias entre aquellas series. Estas interpretaciones han supuesto una estrecha e inalterable relación entre los niveles de renta y mortalidad de aquellos países, y de este modo, la más elevada mortalidad de España a mediados del siglo XIX se ha explicado de la misma forma que a mediados del $\mathrm{xx}$, por los inferiores niveles de renta de este país. El segundo y principal objetivo de este trabajo es completar las estimaciones regionales de la mortalidad española para antes de 1960, lo que se resuelve con la evaluación de la mortalidad de un grupo relativamente amplio y significativo de edades que es el constituido por los menores de quince años. Este análisis de los diferenciales regionales entre 1860 y 1960 enriquece el cuadro español de la mortalidad y ayuda a comprender mejor el mapa y evolución general de la mortalidad europea. A través del caso español se verá, por ejemplo, cómo cambió la relación entre la renta y la mortalidad a lo largo de aquel período y, en el último apartado de este artículo, se examinarán las razones de aquellos cambios.

\section{SERIES EUROPEAS Y PERSPECTIVAS DE ANÁLISIS}

En 1860, la esperanza de vida de la población española era de veintinueve años, muy inferior entonces a la de los países del norte de Europa, en donde cien años antes ya se habían registrado esperanzas de vida próximas a los treinta y cinco años y en donde además la mortalidad declinó considerablemente, como vemos en el gráfico 1, entre 1780 y 1840 . La distancia que separaba a España de los países del centro y norte de Europa se redujo progresivamente entre 1900 y 1960 . En esta última fecha, las esperanzas de vida de todos aquellos paises, incluido España, eran superiores a los setenta años y desde entonces se hallan dentro de unos márgenes 


\section{GRÁFICO 1}

Evolución de la esperanza de vida al nacer (ambos sexos) en distintos países de Europa, 1740-1990

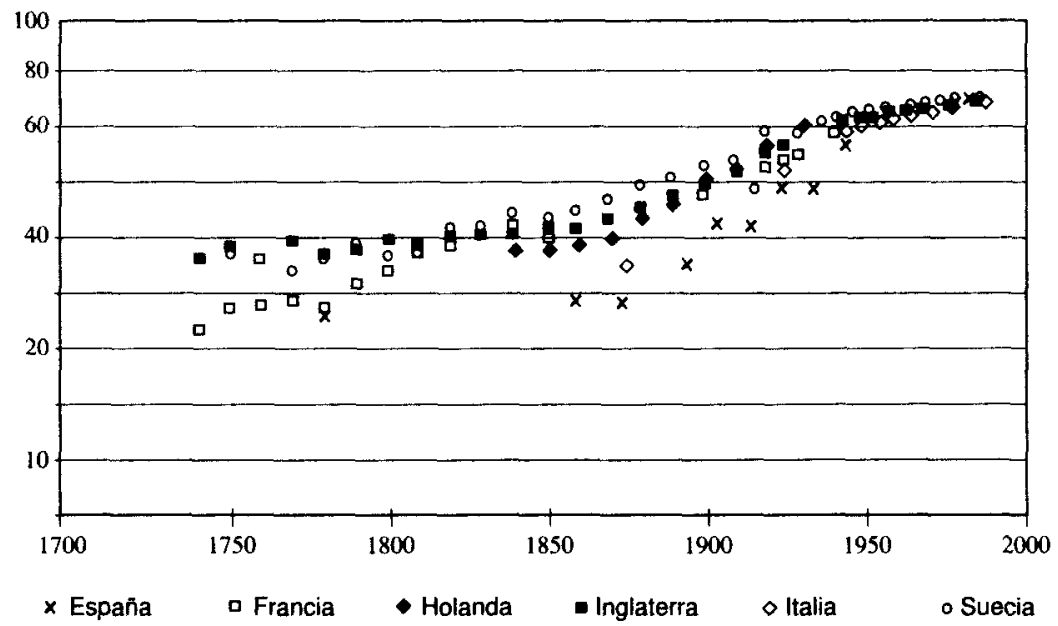

FueNTE: España: 1787, Livi Bacci (1978), p. 181; 1861.1870 y 1878-1882, Instituto Geográfico y Estadístico, Movimiento de la población (1877: pp. 26-36 y 1985: p. 64); 1900-1991, INE (Anuario 1996). Francia, Inglaterra y Suecia antes de 1929: Wrigley (1981), p. 35. Holanda antes de 1950 e Inglaterra después de 1930: Deprez (1979), p. 281. Italia antes de 1962: Del Panta (1979), p. 227. El resto de los datos, Anuarios Demográficos de las Naciones Unidas.

relativamente estrechos, que en 1990 se sitúan entre los setenta y cinco y los setenta y ocho años.

Cuando se dispone de series largas de la esperanza de vida como las del gráfico 1, es tentador establecer comparaciones entre poblaciones en distintas fechas del tiempo. La situación de España a fines del siglo XIX la comparamos por ejemplo a la de Francia o Inglaterra cien años antes, de igual forma que numerosos países en vías de desarrollo después de la Segunda Guerra Mundial los juzgamos en una situación muy similar a la de los países de la Europa mediterránea a fines del XIX. Estas comparaciones son inevitables y además necesarias pero no son suficientes para establecer las evoluciones en el futuro y en el pasado de la mortalidad. Esta precaución muy a menudo la olvidamos y encadenamos unas observaciones a otras para de esta forma simplificar nuestro relato y darle a su vez una explicación global. Un ejemplo de ello es considerar los cambios 
en la mortalidad entre 1780 y 1840 de los países del norte de Europa como cambios innovadores y precursores de los cambios en la mortalidad que iban a producirse significativamente más tarde, con una intensidad y a una escala geográfica mucho más grande a partir de finales del siglo XIX. De esta forma juzgamos la alta mortalidad de los países mediterráneos hacia 1870 , como un reflejo más del atraso de estos países, en particular de su atraso en el proceso de crecimiento económico moderno.

Esta interpretación se basa en el supuesto simplificador de que el declive de la mortalidad fue un proceso unitario que se puso en marcha en el siglo XVIII en unos pocos países, se extendió a partir de 1870 al conjunto de los países occidentales y después de la segunda guerra mundial, al resto del mundo ${ }^{1}$. Esta convicción de que se trata de un proceso único, más lento en los países pioneros que en los del Tercer Mundo, allana los problemas interpretativos. Nos permite reducir el abanico de posibles causas para concentrarnos sólo en aquellas fuerzas más nuevas capaces de explicar un trazo más largo y sobresaliente de la trayectoria de la mortalidad. Estas fuerzas fueron el crecimiento económico moderno o el aumento sostenido de la renta por habitante y el progreso técnico evaluado en este caso por los avances terapéuticos. Como estos últimos se produjeron sobre todo a partir de los años 1930, reservamos al crecimiento económico la explicación del declive de la mortalidad de los países occidentales antes de aquella fecha y atribuimos al progreso médico la difusión de aquel proceso a partir de entonces al resto del mundo ${ }^{2}$.

Dos motivos han alejado a los historiadores de esta interpretación según la cual el incremento de la renta fue el motor del declive de la mortalidad. En primer lugar, la opinión de muchos autores de finales del siglo XvIII y del XIX, que vivieron el inicio de aquellos procesos. La mayoría de ellos tenían razones justificadas para desconfiar de los beneficios que para la salud y la sobrevivencia podían aportar la industrialización, urbanización y el crecimiento económico que ambos procesos generaban. El segundo motivo son las evidencias empíricas más sólidas que ahora disponemos sobre la evolución de la mortalidad antes de 1870. En los últimos años se ha conseguido, por ejemplo, prolongar para algunas poblaciones las series

${ }^{1}$ Wrigley (1993) define y critica este concepto de proceso unitario al referirse al proceso de la Revolución Industrial. En nuestra opinión sus críticas son aplicables también al proceso de la transición demográfica, y en particular a la transición de la mortalidad, que es el tema aquí analizado.

${ }^{2}$ La obra de Mckeown (1978) contribuyó de una forma importante a establecer esta interpretación. 
del gráfico 1 hasta cubrir parte de los siglos anteriores ${ }^{3}$. De esta forma se ha descubierto que las esperanzas de vida más altas a mediados del siglo XIX de los países del norte de Europa ya se habían alcanzado en algunas poblaciones y conservado además durante intervalos de tiempo relativamente prolongados. Desde esta nueva perspectiva, las esperanzas de vida de 1840 no nos parecen tan excepcionales como se había creído $\mathrm{y}$ las mejoras de finales del siglo xvII y principios del $\mathrm{xIX}$ tampoco debieran juzgarse tan rápidamente como un resultado inequívoco de la nueva sociedad industrial emergente ${ }^{4}$.

Esta nueva perspectiva abierta por las series europeas orientará el trabajo de las páginas siguientes en las que nos proponemos analizar los diferenciales regionales de la mortalidad española a mediados del siglo XXX y su evolución posterior hasta $1960^{5}$. Se verá que a finales del siglo $\mathrm{xx}$, en un momento en que los diferenciales regionales de la mortalidad eran muy significativos, las regiones con rentas relativamente más elevadas no disfrutaban en cambio de mejores niveles de sobrevivencia. Se criticará entonces aquella interpretación del declive secular de la mortalidad que ha primado desde una fecha muy temprana el papel del crecimiento económico moderno y ha postergado en cambio hasta una fecha relativamente tardía el impacto del progreso en los conocimientos médicos. Se valorarán finalmente los descubrimientos microbiológicos de finales del siglo XIX y

${ }^{3}$ El caso de Inglaterra es el más conocido gracias a la obra de Wrigley y Schofield (1981), pero para otros ejemplos ver Perrenoud (1984).

4 Esta nueva perspectiva de análisis de los cambios de la mortalidad entre 1780 y 1840 se halla en diversos de los trabajos reunidos en Bengtsson, Fridlizius y Ohlsson (1984) y Schofield, Reher y Bideau (1991).

${ }^{5}$ A partir de 1960, disponemos de estimaciones sistemáticas y completas de la mortalidad de las regiones españolas establecidas por el Instituto Nacional de Estadística y el Centre d'Estudis Demogràfics, ver INE (1978) y Devolder (s. f.). Las primeras tablas provinciales de mortalidad publicadas por el INE de los años 1959-1960 ya señalaban un estrechamiento muy significativo de las esperanzas de vida regionales y un acercamiento notable de todas ellas a los niveles europeos. Distintos autores han contribuido a llenar el vacio existente antes de 1960: aportando nuevas estimaciones de la mortalidad infantil Gómez Redondo (1992); reconstruyendo series largas para los siglos XIX y XX de la mortalidad infantil y juvenil en un gran número de localidades españolas Sanz Gimeno (1999) y Reher, Pérez-Moreda y Bernabeu-Mestre (1997). Para la estimación de la mortalidad a todas las edades y la construcción de tablas regionales antes de 1960 ver trabajo recientemente publicado de Dopico y Reher (1998). Los indicadores de la mortalidad española que se presentan en los mapas 1 a 8 y gráfico 2 han sido calculados por nosotros. Los de los mapas 1 , 3 y 6 pueden compararse con los de Dopico y Reher (1998); las diferencias más significativas en el procedimiento de cálculo se encuentran en las estimaciones de 1860 (ver mapa 1 y nota 7), para los años 1910 y 1930 las diferencias más importantes entre aquellos autores y nosotros son sólo los años escogidos para el cálculo. 
se mostrará cómo éstos ampliaron las posibilidades de intervenir sobre la salud y la sobrevivencia y cómo éstos convirtieron a la renta en una variable a partir de entonces significativa en la determinación de los niveles y disparidades de la mortalidad.

Se quiere mostrar que el progreso en los conocimientos, el avance en la intervención sanitaria y el consiguiente aumento de la esperanza de vida son componentes fundamentales del bienestar y la riqueza de las regiones. Con ellos no se pretende desbancar ni reemplazar a otros indicadores convencionales como el de la renta por habitante, lo que se quiere simplemente mostrar es que los procesos de cambio en el largo plazo son el resultado de un haz múltiple de fuerzas y que indicadores sintéticos, como el de la renta por habitante, que resumen un amplio espectro de estas fuerzas, han tenido una conversión en índices de salud y sobrevivencia muy distinta a lo largo del tiempo. En definitiva queremos recordar que los atributos de la riqueza (o de la pobreza) son de naturaleza muy diversa y además no se presentan siempre juntos ni en las mismas proporciones y por lo tanto es necesario también aislarlos y valorarlos separadamente.

Como especifica el título, en este artículo se analizará sólo la mortalidad de los más jóvenes y en particular de los menores de quince años. Dos razones han justificado esta elección. En primer lugar, el hecho bien demostrado de que los progresos en la esperanza de vida se han debido fundamentalmente a la reducción de la mortalidad infantil y juvenil y es por lo tanto en estos grupos de edades donde se hallan las mayores diferencias de mortalidad entre las poblaciones de los siglos $\mathrm{xIX}$ y $\mathrm{xx}^{6}$. Al fijar nuestra atención en los menores de quince años sabíamos por lo tanto que examinábamos uno de los componentes más importantes del descenso de la mortalidad. El otro motivo del interés por estas edades es que las carencias de salud de los más jóvenes tienen importantes repercusiones sobre la población activa, sobre el número de efectivos y sobre muchas otras de sus características. Aunque este aspecto no se va a desarrollar aquí, justificaba también aquella elección de estudiar la mortalidad durante los primeros quince años de vida o lo que hemos preferido llamar antes de entrar (entiéndase plenamente) en la vida activa.

' En las tablas modelo de mortalidad de Coale y Demeny (1983) construidas a partir de las tablas reales de una amplia gama de poblaciones, las tablas españolas de principios del siglo XX constituyen un ejemplo muy relevante de lo que ha venido en llamarse el Modelo de Tablas Sur. Estas tablas se distinguen de las de la mayoria de los países occidentales (Tablas Oeste, Norte y Este) por la elevada mortalidad en el grupo de uno a cuatro años de edad. Este rasgo de las tablas españolas se encuentra también en las tablas de otros países de la Europa del sur, africanos y de otras regiones muy cálidas. 


\section{LAS DISPARIDADES REGIONALES DE LA MORTALIDAD ESPAÑOLA}

El gráfico 1 mostraba la distancia que separaba a España de Suecia, Inglaterra o Francia hacia 1860 . Advertimos que el atraso español no debía juzgarse rápidamente ya que los progresos de otros países antes de aquella fecha podían no estar, o sólo accidentalmente, relacionados con el crecimiento económico moderno. La misma prudencia interpretativa se recomienda ahora antes de examinar el mapa 1, donde se muestra un indicador de las diferencias provinciales de la mortalidad de los jóvenes españoles en $1860^{7}$. Aunque las mayores proporciones de sobrevivientes a los quince años de edad se hallen en la cornisa cantábrica esto no debiera aún interpretarse como una señal de que aquellas regiones ya habían empezado el declive moderno de la mortalidad. Antes de entrar en la interpretación de estas diferencias, es preciso valorar críticamente las estimaciones que aquí se presentan y asegurarse sobre todo de que este mapa no es el resultado de la desigual calidad regional de los datos que manejamos.

La mayor parte de los datos utilizados, los nacimientos y defunciones por edades proceden de las estadísticas del movimiento natural. Estas estadísticas eran deficientes en el siglo XIX y sólo publicaron datos detallados a escala provincial o regional durante la década de 1860 , por lo que con dicha fuente no pueden establecerse otras estimaciones de la mortalidad regional para otros momentos del siglo pasado. Aunque los resultados de 1860 muestran una coherencia regional muy sobresaliente, podría temerse que dicha coherencia fuera una falsa pista y fuera el resultado en realidad de que el subregistro en las estadísticas del movimiento natural presentase una determinada pauta regional. Podría suceder, por ejemplo, que en las regiones de la cornisa cantábrica, con una población más dispersa y unas tasas de emigración a ultramar muy elevadas, el registro de los nacimientos y defunciones estuviera peor establecido y fuera por lo tanto más deficiente que en el resto de la península. El análisis efectuado sobre la calidad de

${ }^{7}$ En dicho mapa como en algunos otros que le siguen se presenta un indicador sintético de los niveles de mortalidad antes de los quince años. Este indicador se elabora a partir del cálculo de las probabilidades de muerte (o lo que es su complementario, las probabilidades de sobrevivencia) durante un período de tiempo determinado, indicado en cada mapa, y que en este caso son los años 1860-1862. A partir de estas probabilidades de muerte y sobrevivencia se estima la proporción de efectivos que sobre una generación de mil nacidos llegarían a cumplir los quince años de edad, dadas las condiciones de mortalidad del período examinado. Se trata, pues, de la proporción de sobrevivientes a los quince años de edad de la tabla de mortalidad de aquel momento. 


\section{MAPA 1}

Proporción de sobrevivientes a los 15 años de edad, en 1860-1862

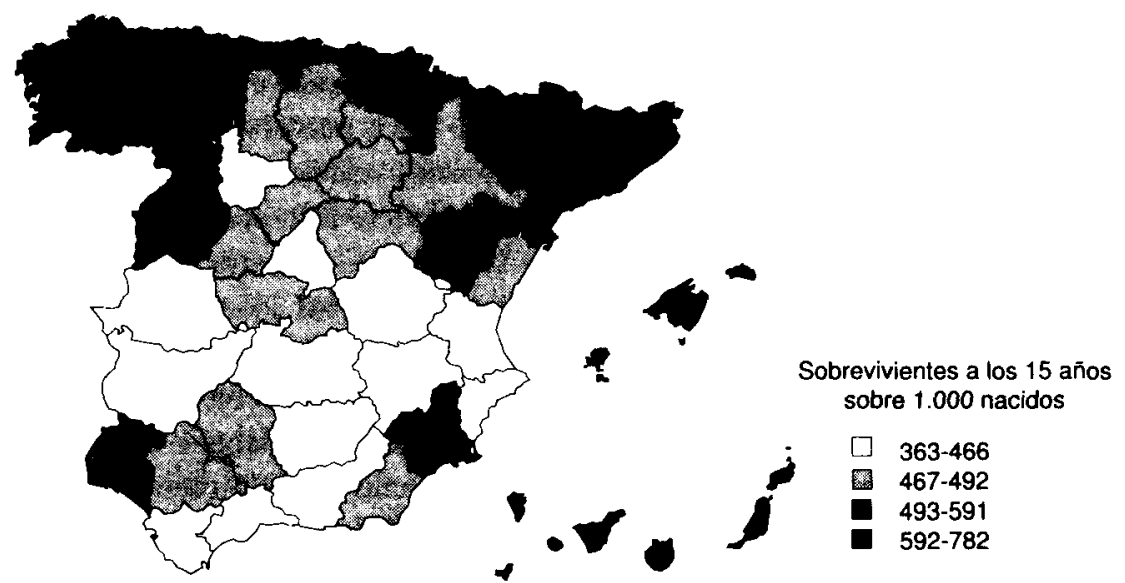

FUENTE: A partir del censo de la población de 1860 y las estadísticas del movimiento natural de $1860-1862$.

los datos y las estimaciones que manejamos del grado de subregistro de las distintas fuentes (de nacimientos, defunciones y población censal) no señalan, sin embargo, esta posibilidad ${ }^{8}$. Las provincias con mayor subregistro y peor calidad de los datos se hallan dispersas en distintas regiones del país y presentan por lo tanto una pauta muy diferenciada a la del mapa 1. Otros análisis, basados por ejemplo en el contraste con las fuentes parroquiales, permitirán en el futuro establecer correcciones y estimaciones mejores de la mortalidad que las que aquí presentamos. Pero antes de que esto sea posible, se quieren explorar aquí otros procedimientos indirectos y alternativos de evaluar esta variable que aporten un mayor grado de convicción a los valores del mapa 1.

Para evitar el problema del subregistro de las defunciones, se buscó otra forma de estimar la mortalidad de los jóvenes, a partir de una fuente distinta a las estadísticas del movimiento natural. Los censos de población ofrecen esta posibilidad cuando en su cuestionario incluyeron una pregunta

${ }^{8}$ Muñoz (1998), «La mortalidad de los niños en la España de 1860: evaluación de los datos y propuesta de reconstrucción» (mimeo). Este estudio forma parte de un trabajo en curso de realización de este autor junto con Nicolau, cuyo objetivo es reconstruir los niveles y disparidades regionales de la mortalidad durante la segunda mitad del siglo $\mathrm{xIX}$, explorando vías alternativas a las utilizadas por Dopico (1987). 
dirigida a las mujeres casadas sobre el número de hijos que habían tenido y el número de ellos que habian fallecido antes del censo. Dado que se trata de una pregunta retrospectiva, en las respuestas podían producirse olvidos u omisiones, sobre todo de aquellos hijos fallecidos a una edad muy temprana. Esta fuente es probable por lo tanto que también subestime la mortalidad. Sin embargo, las razones que producen los sesgos de esta fuente y de las estadísticas del movimiento natural son de naturaleza distinta, sería entonces casual que allí donde las estadísticas del movimiento natural fueran más deficientes, las respuestas de las mujeres en los censos también fueran más inexactas.

Aquella pregunta fue incorporada en los censos españoles a partir de 1920 y, por lo tanto, ésta es la primera fecha en la que puede calcularse la proporción de hijos aún sobrevivientes sobre el total de hijos que tuvieron las mujeres casadas. Del censo de 1920 se examinaron las mujeres de treinta y seis a cuarenta y cinco años ya que las de más edad, que nos hubieran acercado más a la mortalidad del siglo XIX, se agrupaban en un intervalo abierto y demasiado amplio de edades, de cuarenta y seis y más años. Las mujeres escogidas habían tenido la mayoría de sus hijos después de 1905 y lo que se valora por lo tanto en el mapa 2 es la mortalidad entre aquel año y 1920. Las proporciones más elevadas de sobrevivientes se hallan en las dos franjas costeras del norte y este de la península. Aunque cerca de cincuenta años separen el mapa 1 del 2 y la fuente utilizada en cada uno de ellos sea distinta, las regiones de la cornisa cantábrica presentan unas proporciones de jóvenes sobrevivientes significativamente superiores a las de las regiones del centro y del sur de la península. Las estadísticas del movimiento natural de los años 1909-1912, véase ahora el mapa 3, corroboran la ventaja comparativa de aquellas regiones ${ }^{9}$. Estas estadísticas así como el censo de 1920 descubrían otra área al este de la península en donde las proporciones de sobrevivientes también eran superiores a las de las provincias interiores y del sur. Sin embargo, estas regiones mediterráneas en 1860 no parecían disfrutar aún de aquella situación privilegiada. ¿Cómo podría confirmarse su distanciamiento en 1860 de las de la España atlántica y su posterior acercamiento en la segunda década del siglo $\mathrm{XX}$ ?

${ }^{9}$ En este mapa, como en los posteriores, los cocientes de mortalidad infantil han sido corregidos para tomar en consideración los fallecidos antes de las veinticuatro horas de su nacimiento. En 1909-1912 se han corregido según e! procedimiento propuesto por Nicolau (1989), vol. II, p. 75. A partir de 1930 se han utilizado las tasas de mortalidad infantil corregidas por Gómez Redondo (1992), pp. 240-241. 


\section{MAPA 2}

Proporción de hijos sobrevivientes de las mujeres casadas de 35-45 años, en 1920

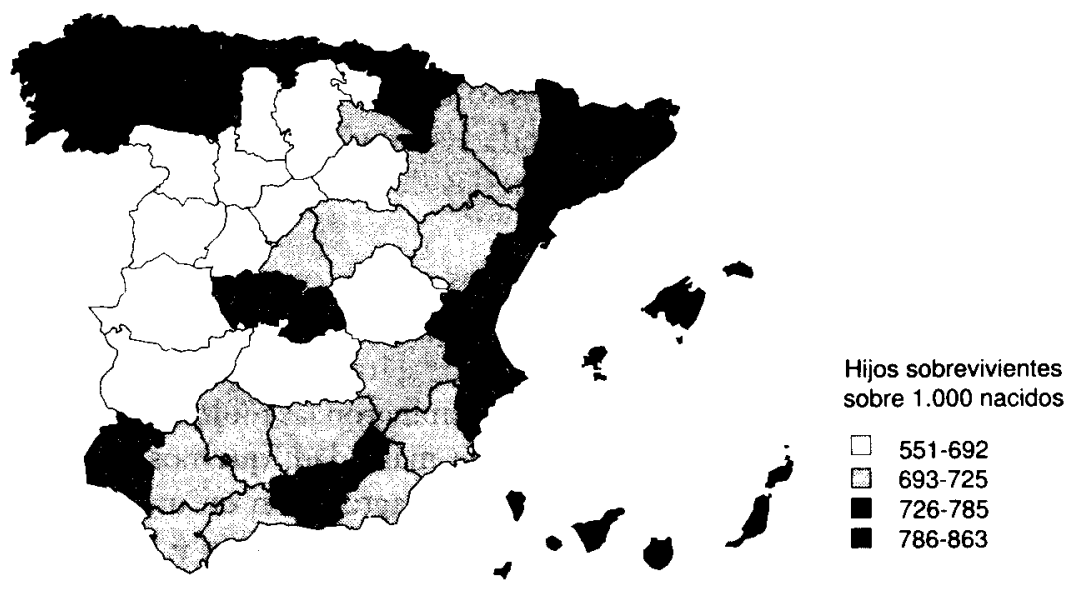

FUENTE: A partir del censo de la población de 1920.

Las estadísticas de las causas de muerte aportan respuestas inmediatas a algunas de las preguntas planteadas por los mapas anteriores. Estas estadísticas disponibles en muchos países han mostrado que cuando la mortalidad es muy elevada, las causas de muerte más frecuentes entre los menores de quince años son las infecciones respiratorias y digestivas ${ }^{10}$. Estas últimas fueron en concreto las responsables de la sobremortalidad española en relación a los países del norte y centro de Europa y de la acusada sobremortalidad en particular de los niños de uno a cuatro años de edad. A partir de esta observación, realizada sobre las estadística nacionales, establecimos la hipótesis de que las regiones españolas con mayores niveles de sobrevivencia durante la segunda mitad del XIX y primera del $\mathrm{xx}$ padecían probablemente menos aquellos dos conjuntos de patologías y en particular menos infecciones digestivas. La distinta incidencia regional de estas infecciones era otra forma entonces de confirmar y a la vez explicar las disparidades internas de la mortalidad española observadas en los mapas precedentes.

${ }^{10}$ Para una comparación de los niveles y las estructuras por edades y causas de la mortalidad en un amplio número de países ver Preston (1976). 


\section{MAPA 3}

Proporción de sobrevivientes a los 15 años de edad, en 1909-1912

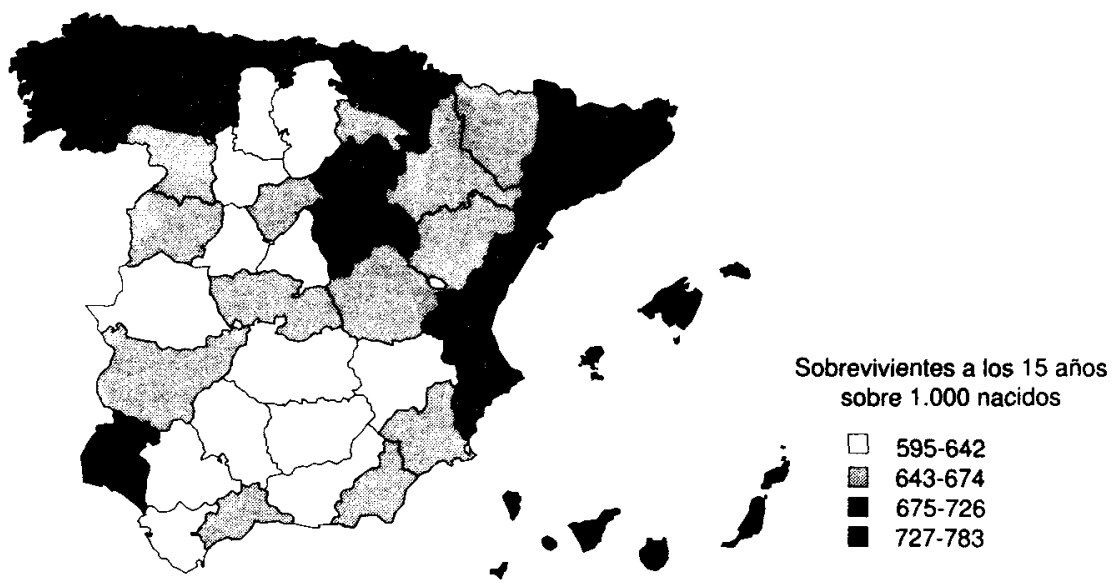

FuentE: A partir del censo de la población de 1910 y el movimiento natural de 1909-1912.

La verificación de esta hipótesis encontró una serie de problemas. En primer lugar, la clasificación de las defunciones por causas era pésima en las estadísticas de los años 1860. Una forma de esquivar este problema fue evaluar la sobremortalidad en los meses de verano, durante los cuales se concentraban la mayor parte de las defunciones por infecciones digestivas ${ }^{11}$. Se calculó entonces la proporción de defunciones de los meses de julio, agosto y septiembre de los años 1863-1864 que son los primeros años para los que disponemos de las defunciones provinciales clasificadas por meses. Si aquellas defunciones se hubieran distribuido regularmente a lo largo del año y si se considera que todos los meses tuvieran la misma duración en días, la proporción estival sería de 300 , sobre un total de 1.200 defunciones anuales. Esta proporción, como vemos en el mapa 4, era superada ampliamente en la mayoría de las regiones españolas. Sólo un grupo muy reducido de provincias no presentaba aquella pauta de acusada sobremortalidad veraniega. Se trataba de un grupo compacto constituido por las provincias gallegas, del resto de la cornisa cantábrica y las

${ }^{11}$ Otros trabajos sobre la estacioralidad de la mortalidad en España y otros países mediterráneos son los de Sánchez Albornoz (1975), Sáez (s. f.), Biraben y Henry (1958), Breschi y Livi Bacci (1986). 
MAPA 4

Proporción de defunciones estivales sobre el total anual, en 1863-1864

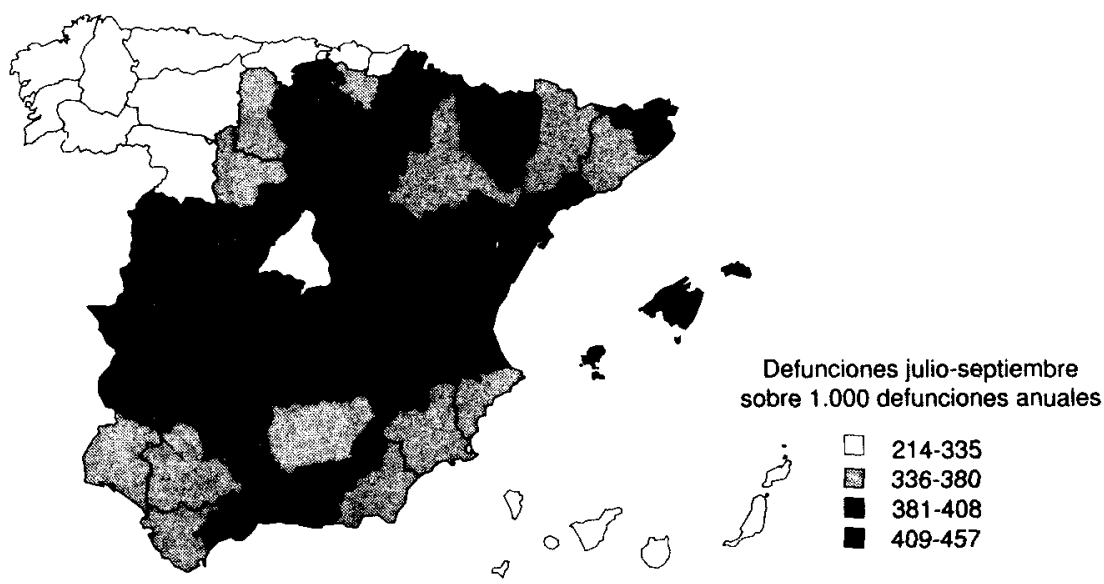

FUENTE: A partir de las estadísticas del movimiento natural de 1863.1864.

provincias de León y Zamora. Aunque en Madrid tampoco se observa una sobremortalidad veraniega, el caso de esta provincia debe considerarse como un caso aparte debido al fuerte peso que tenía en esta provincia la capital, que como otras ciudades tenía unas pautas de mortalidad distintas a las de las poblaciones rurales y núcleos de población de menor tamaño ${ }^{12}$.

A principios de siglo, la clasificación de las causas de muerte mejoró significativamente pero a escala provincial tardó en publicarse por grupos de edades. En 1910 entre las distintas causas se especificaron sin embargo «las defunciones por diarreas y enteritis de menores de dos años», lo que permite examinar la distinta incidencia regional de estas infecciones sobre el grupo de edades más afectado por ellas que eran los niños de pocos meses y en particular los que se hallaban en período de destete. En el mapa 5 se han representado las tasas provinciales de mortalidad de los menores de dos años por «diarreas y enteritis» en 1910-1911. Las dos cornisas, Cantábrica y este del Mediterráneo, mostraban entonces una

12 A pesar de ostentar los peores indicadores de supervivencia, la provincia de Madrid tiene un patrón estacional de mortalidad claramente invernal. Esto se explica porque en las ciudades, la estructura por edades de la población está muy afectada por el fenómeno migratorio y las más favorables condiciones para la propagación de infecciones respiratorias provocan una sobremortalidad invernal que oculta la también alta mortalidad infantil-estival. Ver Cussó (2000). 


\section{MAPA 5}

Tasa de mortalidad de los menores de dos años por diarrea y enteritis, en 1910-1911

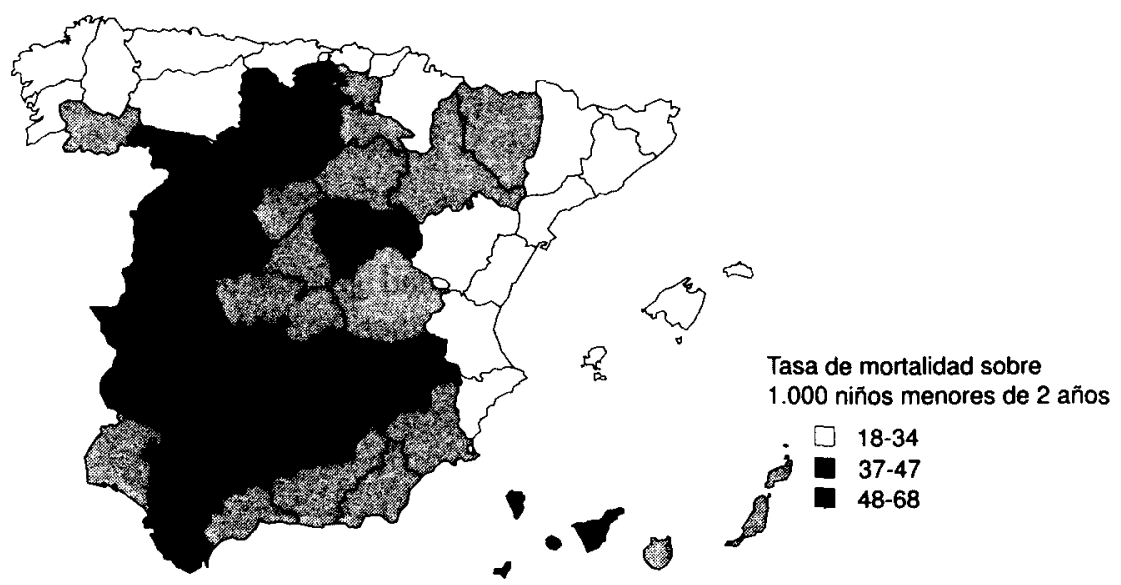

FUENTE: A partir del censo de la población de 1910, el movimiento natural de 1910-1911 y el Boletín Mensual de Estadística Demográfico-Sanitaria, de 1910-1911.

menor incidencia de aquel tipo de infecciones. Las diferencias eran bastante significativas, lo que nos lleva a creer que ésta fue una de las causas principales de los mejores niveles de sobrevivencia de aquellas regiones en relación a las regiones interiores y del sur de la península.

El análisis del movimiento estacional en los años 1860 y de las causas de muerte en 1910 señalan en definitiva que las proporciones de sobrevivientes en la cornisa cantábrica eran más elevadas porque la incidencia allí de las infecciones digestivas era menor y por esta razón se producía una menor frecuencia también de defunciones durante los meses de verano. Aunque en 1860, en las regiones del este mediterráneo, la mortalidad por estas infecciones era elevada disminuyó significativamente entre 1860 y 1910 , de tal modo que en esta última fecha aquellas regiones ya alcanzaban a las atlánticas y compartían con ellas los mejores niveles de sobrevivencia de toda la península.

En 1930, la mortalidad española conservaba aún su anterior carácter regional aunque la esperanza de vida del conjunto de la población era de cincuenta años y se encontraba a medio camino entre la de 1860 (veintinueve años) y la actual de setenta y siete años. La diferencia respecto 
a 1910 más significativa, como puede verse en el mapa 6, era que las regiones más urbanizadas, como Cataluña y el País Vasco, destacaban entonces por sus elevados niveles de sobrevivencia sobre el resto de las regiones atlánticas y mediterráneas y que Madrid por primera vez se distinguía con una mortalidad inferior del resto de provincias del interior. A partir de 1931, la clasificación de las causas de muerte mejoró significativamente, se adaptó a los nuevos criterios internacionales revisados en la década de 1920 y se clasificaron las defunciones por provincias, edades y las nuevas categorías de causas de muerte, simultáneamente. Gracias a aquella mejora es posible a partir de entonces medir separadamente el peso de las distintas causas sobre la mortalidad general de los jóvenes. El procedimiento utilizado ha sido calcular el número medio de años vividos por una generación antes del 15 aniversario. La diferencia entre 15 y aquel número indica el número medio de años perdidos por todas las causas antes del 15 aniversario. A partir de las tasas de mortalidad por edad y causa se ha determinado la parte de aquellos años perdidos correspondiente a cada causa y en concreto a la mortalidad por diarrea-enteritis y a la mortalidad por gripe-bronquitis-neumonía ${ }^{13}$.

En 1931, estos dos grupos de enfermedades, agrupadas con las denominaciones «diarreas-enteritis» y «gripe-bronquitis-neumonía» causaban más de la mitad de las defunciones de menores de quince años registradas en España ${ }^{14}$. El primer grupo era el que ocasionaba mayores pérdidas en años de vida entre los jóvenes españoles. La incidencia regional de las infecciones digestivas era además muy variable y como vemos en el mapa 7, allí donde las infecciones digestivas eran menos virulentas, en las provincias limítrofes del norte y este de la península, las probabilidades de sobrevivencia de los jóvenes eran por ello notablemente superiores.

Las infecciones respiratorias y en particular las que vemos en el mapa 8 agrupadas con la denominación «gripe-bronquitis-neumonía» eran el segundo grupo de causas de muerte más importante entre los jóvenes. Estas infecciones eran menos graves y causaban menos pérdidas en las provincias litorales del noreste, este y sur de la península. Estas infecciones deter-

${ }^{13}$ Se han utilizado las relaciones entre tasas de mortalidad y esperanzas de vida formuladas por Pollard (1982).

${ }^{14}$ La tercera causa importante era la denominada «debilidad congénita y vicios de conformación» que con un 13 por 100 de defunciones afectaba casi exclusivamente a los menores de un año. La meningitis y el sarampión con porcentajes próximos al 3 por 100 eran las que seguían en importancia a las anteriores. El resto de las defunciones se distribuían entre un grupo relativamente amplio de causas que sumaban un total de 43 denominaciones, adaptadas como ya se ha dicho a las recomendaciones internacionales de aquel momento. 


\section{MAPA 6}

Proporción de sobrevivientes a los 15 años de edad, en 1929-1932

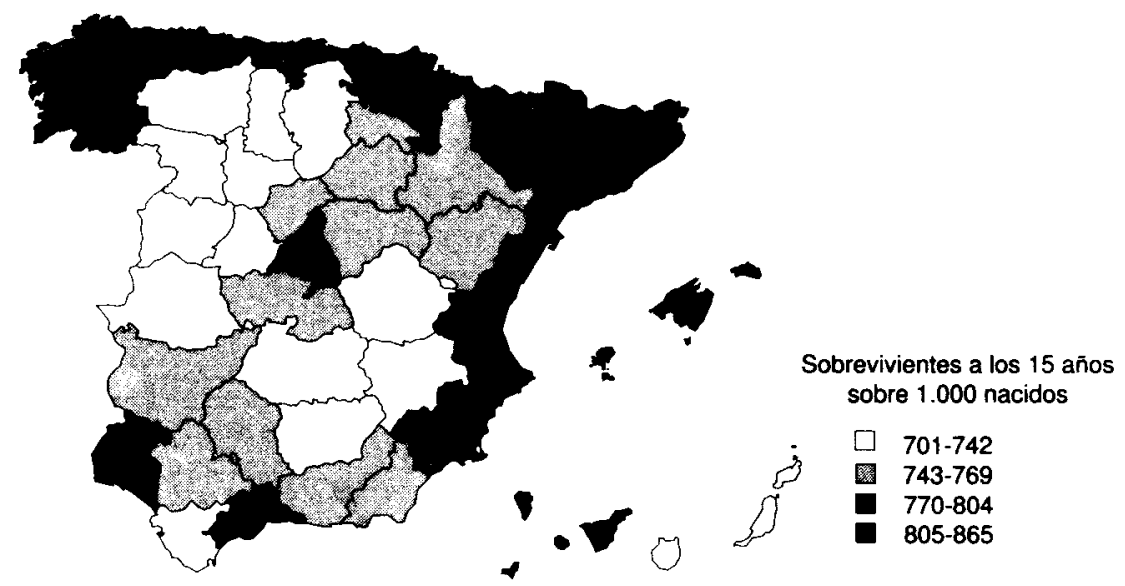

Fuente: A partir del censo de la población de 1930 y del movimiento natural de 1929-1932.

minaban finalmente que la mortalidad general de los jóvenes fuera más elevada en las dos Mesetas que en Andalucía, ya que a los riesgos que acompañaban entonces los veranos muy cálidos y secos de la mayor parte de regiones de la península se añadían también allí los riesgos de unos inviernos más fríos que en el sur y el litoral.

A partir de los años 1950 se dispone de estimaciones sistemáticas y regulares de la mortalidad de las provincias españolas que pueden además contrastarse con las estimaciones mejor establecidas a partir de entonces de los niveles de renta provinciales y regionales. El gráfico 2 muestra la relación entre aquellas dos variables, las probabilidades de sobrevivencia de los jóvenes y las rentas medias, en las 17 Comunidades Autónomas actuales a principios de los años 1950 , en un momento en que las diferencias regionales de la mortalidad eran aún muy acusadas ${ }^{15}$.

${ }^{15}$ Para hallar los valores por Comunidades Autónomas del gráfico 2, se han calculado medias ponderadas, según el número de habitantes, de los datos provinciales del ingreso por habitante en 1955 [véase Banco de Bilbao (1978), pp. 104] y de las proporciones de sobrevivientes a los quince años de edad [calculadas a partir del censo de población de 1950, del movimiento natural de $1949-52$ y de los cocientes de mortalidad infantil corregidos por Gómez Redondo (1992), pp. 259-262, y Cussó (2000)]. 


\section{MAPA 7}

Número medio de años perdidos antes del 15 aniversario, por causa de diarrea $y$ enteritis, en 1931

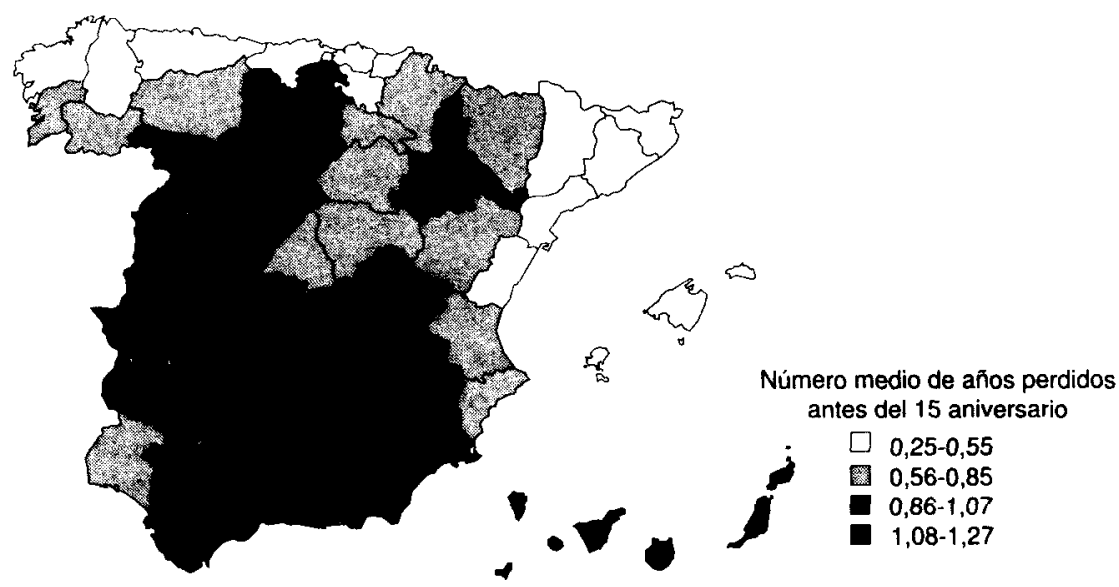

Fuente: A partir del censo de la población de 1930 y del movimiento natural de 1930-1931.

Las regiones con una renta por habitante superior a la media española disfrutaban de unas proporciones de sobrevivientes a los quince años también más elevadas, pero por lo que se ha visto en las páginas anteriores, algunas de estas regiones, como Cataluña, Valencia y Madrid, no consiguieron aquellos niveles de sobrevivencia más elevados hasta la segunda década del siglo xx. No obstante, más allá de esta burda distinción entre las regiones con niveles por encima o inferiores a la media española, la correspondencia entre los niveles de renta y de sobrevivencia no era demasiado ajustada. Con los mismos niveles de renta hallamos regiones con niveles de mortalidad bastante diferentes, lo que significa que en los años 1950 otras variables influían también, además de la renta media regional, en la mortalidad. En las páginas siguientes se analizarán aquellos otros factores que determinaron los mapas de la mortalidad española entre 1860 y 1960 y se explicará por qué las regiones con más renta no consiguieron un avance significativo en términos de salud y sobrevivencia hasta las primeras décadas del siglo $\mathrm{xx}$. 


\section{MAPA 8}

Número medio de años perdidos antes del 15 aniversario, por causa de gripe-bronquitis-neumoría, en 1931

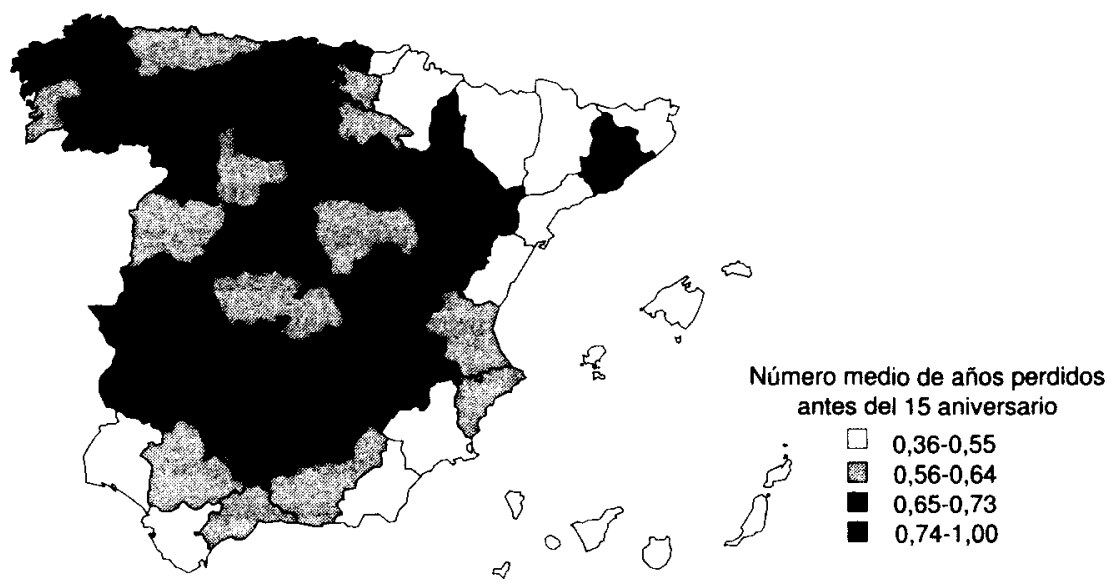

FuENTE: A partir del censo de la población de 1930 y del movimiento natural de 1930-1931.

\section{LOS DETERMINANTES DE LA MORBILIDAD Y LA MORTALIDAD DE LOS JÓVENES}

Hasta mediados del siglo $\mathrm{xx}$, el sector de la población que estamos analizando, los menores de quince años, era muy vulnerable a infecciones digestivas y respiratorias relativamente corrientes que los países occidentales no han conseguido aún hoy en día controlar completamente. Aquellas infecciones, como se ha visto, causaban un porcentaje muy elevado de defunciones en los primeros años de vida ${ }^{16}$. El primer lugar lo ocupaba un grupo de infecciones, de etiología muy diversa y difíciles de precisar incluso hoy en día, clasificadas por su común sintomatología con la denominación de «diarreas y enteritis». El segundo lugar lo ocupaban las agrupadas con la denominación «gripe-bronquitis-neumonía» porque muy a menudo

${ }^{16}$ En los otros grupos de edades, los niveles y estructuras por causas de la mortalidad eran muy diferentes. Los adultos jóvenes, por ejemplo, eran menos vulnerables a estas infecciones digestivas y respiratorias corrientes. Les ocasionaban más muertes las infecciones específicas que como la tuberculosis se ha podido precisar mejor su etiologia, hallar vacunas y tratamientos terapéuticos específicos que han conseguido prácticamente erradicarlas. 


\section{GRÁFICO 2}

Relación entre las proporciones de sobrevivientes a los 15 años de edad y el ingreso medio por babitante, por Comunidades Autónomas, 1950-1955

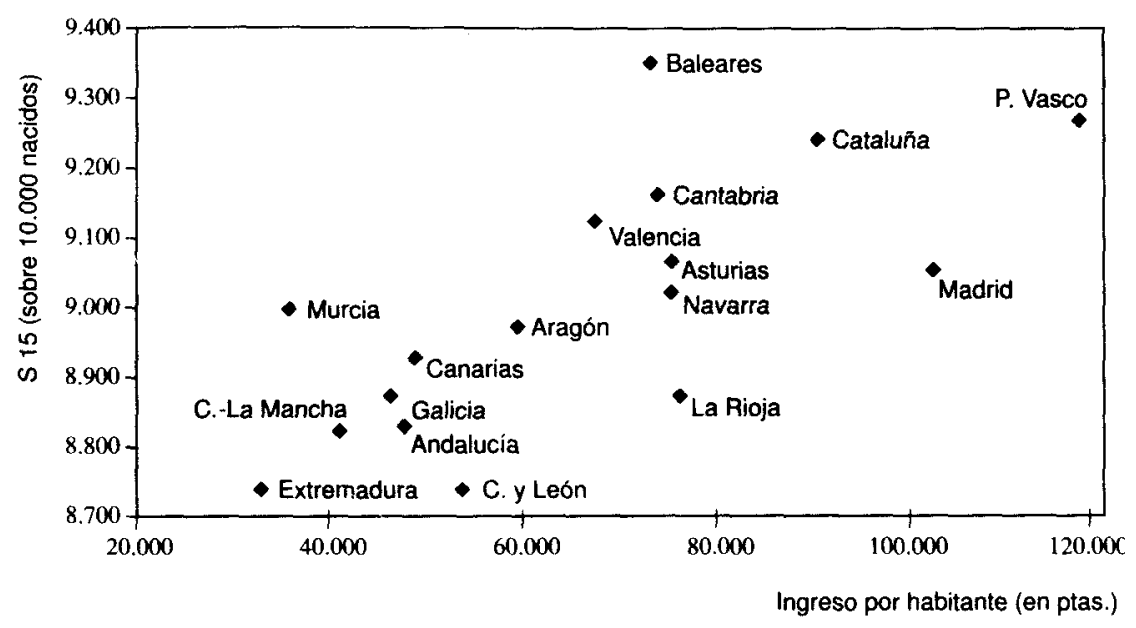

empezaban con una infección respiratoria viral relativamente benigna que se complicaba más tarde y podía desencadenar una neumonía bacteriana.

Estos dos tipos de infecciones digestivas y respiratorias se presentan de una forma recurrente durante la infancia de tal modo que en la mayor parte de las ocasiones, la mortalidad a estas edades no era la consecuencia de un acontecimiento biológico singular sino el resultado de una serie acumulativa de episodios mórbidos y de sus sinergias biológicas que debilitaban al niño y reducían así progresivamente sus probabilidades de supervivencia. Los factores que intervenían en esta sinergia eran múltiples ${ }^{17}$. En primer lugar, la fiebre y el malestar general que acompañan la infección causaban una pérdida del apetito a lo que se sumaba también, en el caso de las infecciones digestivas, la deficiente absorción de los alimentos consumidos, provocada por la distensión abdominal característica de aquel tipo de enfermedades. Para reducir los efectos de la pérdida del apetito y la deficiente absorción de los alimentos debe modificarse la dieta de tal forma que ésta presente una forma más apetecible para el enfermo y un valor nutritivo

${ }_{17}$ Diversos autores han estudiado las sinergias entre diversas enfermedades entre sí y con el estado nutritivo. Véase Scrimshaw (1990), Mosley y Chen (1984), Lunn (1989). 
superior al de la dieta habitual. La satisfacción del primer requisito implica en muchas ocasiones y sobre todo en el pasado incumplir el segundo y consecuentemente reducir el aporte de calorías, proteínas y vitaminas de la dieta del enfermo. En estas condiciones, no es difícil comprender que los períodos de enfermedad comportasen pérdidas significativas en el peso del enfermo, y que estas pérdidas fueran muy peligrosas durante la infancia porque entonces la frecuencia de estas infecciones era muy elevada y se acortaban demasiado los períodos durante los cuales se recupera el peso perdido y se produce el habitual «estirón» que acompaña y pone fin a la convalecencia. El inevitable retraso en el proceso de crecimiento se convertía finalmente en un factor de riesgo importante para que infecciones relativamente banales se complicaran luego con infecciones asociadas más graves, capaces éstas sí de producir la muerte.

Lo que se quiere mostrar con este razonamiento es que en las regiones donde los riesgos de contraer aquellas infecciones corrientes fueran mayores y aquellos episodios mórbidos fueran por lo tanto más frecuentes, el estado nutritivo de los niños sería peor y sus probabilidades de sobrevivencia serían por ambas razones también menores. Esta relación, entre la morbilidad, el estado nutritivo y la mortalidad de los niños no podemos demostrarla en su totalidad porque existen muy pocas estadísticas de morbilidad. No obstante sí podemos demostrarla parcialmente si admitimos que la morbilidad debía reflejarse en las medidas de crecimiento de los niños para las que presumiblemente existen más fuentes disponibles. Los historiadores españoles han empezado a explorar las estadísticas del estado nutritivo y concretamente las establecidas por los militares en el momento del reclutamiento ${ }^{18}$. El trabajo de Gómez Mendoza y Pérez Moreda publicado en 1985 es un buen ejemplo de esta serie de trabajos. En dicha publicación compararon a nivel provincial las tallas de los «mozos útiles» a principios de siglo y en 1915-1929. En aquellos últimos años, el servicio militar ya era universal y por lo tanto todos los mozos presentes declarados útiles fueron tallados (los que padecían ciertas enfermedades o incapacidades por las que eran declarados inútiles no consideraban necesario tallarlos). El principal problema de este trabajo es saber si los jóvenes presentes y por lo tanto evaluados en las estadísticas militares eran representativos del total de jóvenes de igual edad de la provincia. Dicho en otras palabras, la pregunta es saber si los prófugos presentaban las mismas características

${ }^{18}$ A esta edad, el proceso de crecimiento está prácticamente concluido y la talla cons. tituye un excelente resumen del historial nutricional del individuo. 
de salud y talla que los presentes. Esta pregunta es importante porque el porcentaje de prófugos era elevado y además muy variable según las provincias. La solución que adoptaron los autores de aquel trabajo fue suponer que los prófugos, sobre cuyas características las estadísticas militares no pueden informarnos, eran iguales en talla y salud que los presentes. Este supuesto nos parece discutible. En primer lugar porque creemos que los que tenían una salud y talla suficientes para el servicio militar estaban más interesados en emigrar y en convertirse en prófugos que los que no alcanzaban la talla o padecían enfermedades que les incapacitaban para el servicio militar. Existe otra razón para creer que la emigración y la salud no eran variables independientes como suponen aquellos autores. La emigración a ultramar, aunque no exigía exactamente los mismos requisitos que el servicio militar, requería también una fortaleza y buen estado de salud que permitieran afrontar el esfuerzo migratorio y sobre todo maximizar el nivel de ocupación que era algo fundamental que se buscaba con la emigración. Por estos motivos, nos parece más razonable suponer que los prófugos tenían mejor salud y talla que los presentes evaluados en aquellas estadísticas. Si esto fuera cierto cabría esperar que alli donde el porcentaje de prófugos (y emigrantes al extranjero) fuera más elevado mayor sería la subestimación de la talla establecida a partir de los jóvenes presentes.

Aun con las reservas que se acaban de señalar, a principios de siglo como en los años 1915-1929, los jóvenes presentes en las provincias de la cornisa cantábrica, entonces muy emigratorias, registraron unas tallas medias superiores a los de las regiones interiores y del sur de la península. Las provincias gallegas constituyen la única excepción, pero en ellas el porcentaje de prófugos alcanzaba un tercio de la cohorte de mozos y por esta razón cabe suponer que la subestimación de la talla fuera allí aún más acusada que en las otras regiones emigratorias del país ${ }^{19}$. Además de las provincias del norte, las otras regiones con tallas relativamente altas en 1915-1929 eran Cataluña, Aragón, el norte de Valencia y las provincias insulares. Comprobamos, pues, que en las regiones donde se encuentran las tallas más altas era en donde se encontraban también las mayores proporciones de sobrevivientes a los quince años. La hipótesis de que el estado nutritivo y la mortalidad de los jóvenes eran variables asociadas que dependían ambas de la morbilidad merece por lo tanto ser retenida y explorada

${ }^{19}$ El porcentaje de prófugos de Galicia sólo lo superaban en muy poco las provincias de Oviedo y Almería y en una magnitud bastante superior Canarias. 
con más profundidad, y esto es lo que nos proponemos hacer en las páginas siguientes.

En el caso particular de las provincias de la cornisa cantábrica, los jóvenes registraban una altura superior y unas mayores proporciones de sobrevivientes porque los riesgos de contraer infecciones, en particular digestivas, durante la infancia eran allí menores. Aquellos menores riesgos ambientales les permitían aprovechar mejor su oferta de alimentos, lo que derivaba en un mayor crecimiento físico de los niños. Otro factor que favorecía también a los niños y jóvenes de las regiones de la España húmeda era su más abundante oferta de alimentos de origen animal procedentes de la pesca y la ganadería, entre los que cabe destacar sobre todo la mayor oferta de leche. Para el grupo de edades que estamos analizando, los menores de quince años, el ajuste entre las necesidades y la oferta de alimentos no puede medirse sólo en calorías porque el aporte de proteínas es fundamental en estas edades, y más aún cuando se han de soportar frecuentes infecciones que requieren un mayor aporte de proteínas, vitaminas y minerales que las necesarias para una persona sana. Esta necesidad suplementaria de nutrientes es difícil de cubrir con un dieta compuesta sólo con alimentos de origen vegetal. La ventaja de la carne, el pescado y la leche es que contienen más proteínas, y de mejor calidad, por porción cocinada que la mayoría de los alimentos de origen vegetal. Esta ventaja es sobre todo importante para los niños y los enfermos que necesitan dietas menos voluminosas, más apetecibles y con mayores proporciones de nutrientes que las habituales para una persona adulta y sana. Las estadísticas de producción agraria del siglo xIX y de consumo de leche y otros alimentos de las primeras décadas del xx señalan que en aquellas regiones los niños podían consumir mucha más leche que en las otras regiones españolas, que muestran un significativo atraso en relación a los valores medios de la mayor parte de países europeos ${ }^{20}$.

La población de las regiones de la España atlántica aun siendo en algunos casos muy pobre, como en Galicia, vivía en un contexto ecológico singular que le favorecía en términos de salud y sobrevivencia en relación al resto de la península. Su adaptación a aquellas condiciones ecológicas, formas de poblamiento y particular orientación de su producción alimentaria también les beneficiaron en términos relativos. Aunque sus casas,

20 Nos referimos sobre todo a las estimaciones de producción y consumo de leche establecidas a partir del censo ganadero de 1865, las estadísticas de 1923 y de años posteriores. Para conocer estas estimaciones y sus posibles implicaciones sobre la afecundidad natural» y la mortalidad ver Nicolau (1989) y Cussó (2000). 
vestido e higiene personal fueran peores (y ésta es sólo una valoración hipotética) que en otras regiones de España, su poblamiento más disperso les permitió vivir más aislados y alejados de los gérmenes de sus vecinos. Aunque no estuvieran muy satisfechos de su dieta (como señalan muchos testimonios) ésta benefició su salud y sobrevivencia y sobre todo la de sus hijos ${ }^{21}$. Esta paradoja, como vamos a ver, se explica porque lo que desde un cierto punto de vista fue un inconveniente de su singular orientación productiva se convirtió en cambio en una ventaja adicional para su dieta. La escasa aceptación de algunas de sus principales producciones alimentarias, como las patatas y el maíz, y las dificultades de conservación sobre todo de la leche, limitaron notablemente hasta las primeras décadas del siglo $\mathrm{xx}$ las posibilidades de comercialización de estos productos. Esta dificultad para dar salida a una parte importante de sus productos alimentarios limitó sus relaciones de intercambio en relación, por ejemplo, a otras regiones cerealeras de la península, pero se convirtió en una ventaja en términos dietéticos porque permitió aumentar el consumo local de estos productos y reducir el riesgo de que sectores de la población muy importantes y con escasa capacidad de decisión como los niños no los consumieran. Finalmente, la proximidad a las fuentes de aprovisionamiento de algunos alimentos, y sobre todo la leche, les permitió consumirlos durante mucho tiempo en condiciones higiénicas y nutritivas mejores que en otras regiones de la península.

El motivo por el cual las regiones con rentas relativamente elevadas como Cataluña, Valencia o Madrid no consiguieron tallas más altas ni proporciones de sobrevivientes mejores hasta las primeras décadas del siglo Xx parece ahora más fácil de comprender. Hasta finales del siglo XIX, aquellas regiones no pudieron contrarrestar los inconvenientes que sobre todo para la salud de los niños surgieron asociados al proceso de urbanización y de crecimiento económico. La concentración de la población en áreas reducidas, donde los contactos interpersonales eran mucho más frecuentes y variados, facilitó la difusión de las infecciones respiratcrias. Además el número de potenciales contaminadores del agua, la leche u otros alimentos, a través de los cuales se transmitían muchas de las infecciones digestivas, también aumentó en las ciudades. Hasta finales del siglo XIX, los riesgos ambientales de las ciudades superaron sus posibles ventajas e incluso los sectores de las poblaciones urbanas con rentas más elevadas no eran tam-

${ }^{21}$ O'Grada (1993) sugería algo parecido en el caso de los irlandeses que aunque pudieran ser pobres desde muchos puntos de vista, su estructura de consumo les permitía en cambio que los niños pudieran alimentarse mejor que en muchas otras partes del continente. 
poco inmunes a la contaminación del agua, los alimentos y las muy deficientes condiciones sanitarias del medio urbano.

Las posibilidades de intervenir y reducir los riesgos de las infecciones infantiles, respiratorias y digestivas, fueron muy limitadas hasta finales del siglo XIX. Las prácticas recomendadas por los higienistas en muchas ocasiones eran acertadas pero se basaban en un fundamento teórico incorrecto, lo que reducía notablemente su eficacia y poder de convencimiento. La teoría dominante era aún la miasmática ${ }^{22}$, según la cual los hedores o miasmas eran los causantes de las enfermedades infecciosas y lo que se pretendía por lo tanto con la higienización de las ciudades era alejar de ellas aquellos hedores. No es extraño, por lo tanto, que las recomendaciones de intervención fueran muy variadas y numerosas. Sin embargo, la eficacia de aquellas medidas fue limitada hasta que se descubrió la existencia de los microorganismos y las vías precisas a través de las cuales éstos difundían la infección.

La teoría microbiana permitió que algunas de las recomendaciones de los higienistas, junto con otras prácticas sanitarias, se racionalizaran, sistematizaran y convirtieran en medidas imperativas capaces de modificar el curso de los procesos infecciosos y de interrumpir sus encadenamientos causales ${ }^{23}$. La adopción de aquella nueva teoría fue sin embargo paulatina. En los años 1860, Pasteur demostró que el crecimiento de los microorganismos podía evitarse. En los años 1880, los descubrimientos realizados por Koch del bacilo de la tuberculosis y del vibrión del cólera fueron muy espectaculares porque consiguieron convencer a muchos de que las enfermedades infecciosas tenían una causa necesaria que podía ser bien identificada. Aunque la progresiva identificación de los microorganismos causantes de otras enfermedades fue importante para el éxito de la nueva teoría microbiana, ésta recibió un impulso definitivo cuando se demostró científicamente que algunas prácticas sanitarias reducían los riesgos y la incidencia de algunas infecciones. La prueba de que en las aguas de muchas ciudades se hallaban los vibriones del cólera y la demostración de que la cloración del agua era un procedimiento eficaz para eliminarlos fue decisiva para que muchas ciudades iniciaran y aceleraran las reformas del sistema de alcantarillado y de aprovisionamiento de agua potable. A partir del ejemplo del cólera, los sectores más influyentes de la sociedad, y sobre todo los propietarios que se habían mostrado más reacios a las medidas

${ }^{22}$ Para un análisis de los antecedentes históricos y el fundamento teórico de las políticas higienistas del siglo XIX ver Cipolla (1993).

${ }^{23}$ Ver algunas de las contribuciones en Salomon-Bayet (1986). 
intervencionistas de la administración, comprendieron que su salud dependía también de la de los demás y que por ello la intervención institucional y la mejora de las condiciones colectivas eran imprescindibles.

A partir de los años 1880, el desarrollo de los proyectos de canalización de las aguas fue relativamente rápido. Otros programas de salud pública, y en particular los orientados a mejorar la calidad de otros alimentos, hallaron mayores dificultades para su aplicación y se llevaron a cabo con un retraso considerable. Por ejemplo, en una ciudad relativamente avanzada en cuestiones sanitarias como era Nueva York, en 1911, sólo un 15 por 100 de la leche ofertada era pasterizada cuando la eficacia de este procedimiento era en cambio conocida desde los años $1860^{24}$. Este retraso en el control sanitario de algunos alimentos se debió en parte a las dificultades técnicas de supervisión del proceso de producción y distribución de estos productos dadas las múltiples fuentes de aprovisionamiento y su amplia red de distribuidores. La indiferencia de los consumidores tampoco favoreció la aplicación de aquellos controles, lo que prueba que la teoría de los microbios tardó en calar en distintos campos y comportamientos de la sociedad.

A pesar de las dificultades que se opusieron al desarrollo de los programas de salud pública, las grandes ciudades, durante las primeras décadas del siglo $\mathrm{xx}$, redujeron su mortalidad a un ritmo muy rápido que en ocasiones ha sido comparado al conocido por muchos países en vías de desarrollo a partir de los años 1940. Este hecho muestra que el progreso en los conocimientos a partir de finales del siglo XIX tuvo un efecto comparable a los avances terapéuticos posteriores a los años 1930. La nueva teoría y ciencia de los microbios forjó un cambio profundo en las instituciones que a partir de entonces se orientaron de una forma mucho más decidida y eficaz hacia una creciente intervención sanitaria. Las regiones más urbanizadas y con rentas más elevadas pudieron adelantarse en aquel proceso no sólo porque disponían de un mayor volumen de recursos para dedicarlo a las inversiones sanitarias, sino también porque disfrutaban de mayores economías de escala dado que los costes de muchas de aquellas intervenciones, como la mejora del alcantarillado y del suministro de agua, eran menores en regiones más densas y urbanizadas. Estas regiones, en general, aprovecharon más pronto las posibilidades que ofrecía la nueva teoría microbiana y redujeron antes los riesgos, sobre todo de las enfermedades digestivas, lo que repercutió en una mejorá del estado nutritivo y las probabilidades de sobrevivencia de los más jóvenes.

${ }^{24}$ Este y otros muchos ejemplos son citados en la obra de Preston y Haines (1991). 
Mientras que esto sucedió en las regiones españolas más urbanizadas durante las tres primeras décadas del siglo $\mathrm{xx}$, las regiones agrarias españolas tardaron en cambio más en reducir su atraso en relación a los niveles de mortalidad de los países del norte y centro de Europa. Las desfavorables condiciones climáticas, en particular el calor y falta de agua, obligaban en la mayor parte del país a extremar aún más los controles sanitarios de los alimentos y a ello se sumó, además, la incapacidad de las instituciones, sobre todo locales y de las regiones agrarias, para movilizarse y organizarse. La superación de esta incapacidad institucional y la difusión de los nuevos procedimientos terapéuticos fueron factores mucho más importantes que el aumento de la renta o de la densidad demográfica, que lograron finalmente acercar los niveles de sobrevivencia de estas regiones y del conjunto del país a los niveles medios europeos. No obstante, esto sucedió a finales del período aquí analizado, a partir de mediados del siglo $\mathrm{xx}^{25}$.

Para terminar sólo señalar que el análisis de las disparidades regionales de la mortalidad española corrobora los análisis más recientes de las series europeas y sus diferencias comentadas al inicio de este artículo. El progreso en los indicadores de salud de las poblaciones del norte de Europa estuvo hasta finales del siglo XIX muy poco relacionado o sólo de forma casual con el crecimiento industrial y económico que conocieron algunos de aquellos países. El mapa de la mortalidad española en la segunda mitad del siglo XIX confirma esta falta de relación. Este mapa muestra que las provincias de la España húmeda se acercaban mucho más a los niveles de sobrevivencia del norte de Europa aunque sus rentas fueran en muchas ocasiones significativamente menores a las de otras zonas de la península. Regiones con rentas más elevadas, como Cataluña, Valencia y Madrid, no consiguieron reducir su atraso ni alcanzar niveles de sobrevivencia comparables o superiores a los de la España atlántica hasta el primer tercio del siglo XX. Este hecho demuestra que las posibilidades reales de convertir los ingresos en salud y sobrevivencia cambiaron a partir de finales del siglo XIX con el descubrimiento de la teoría microbiana. La nueva ciencia, además de elevar las proporciones de sobrevivientes, estableció a principios de este siglo una nueva y más estrecha relación entre la renta y la mortalidad. Se ha querido mostrar que los determinantes de la mortalidad no pueden aislarse de una perspectiva histórica, desde la cual puede realmente valo-

${ }^{25}$ En España, entre 1950-1955 y 1970-1975, las disparidades provinciales de la renta se mantuvieron elevadas mientras que ias de la mortalidad se redujeron considerablemente. Ver Cussó (2000). 
rarse el impacto de los conocimientos y de la intervención institucional y en definitiva comprender que una visión de la riqueza o la pobreza desde los ingresos no ha sido ni puede ser nunca suficiente.

\section{BIBLIOGRAFÍA}

BANCO DE BILBAO (1978): Renta Nacional de España y su distribución provincial. Serie bomogénea 1955-1975, Bilbao.

Bengtsson, J.; Fridlizius, G., y Ohlsson, R. (eds.) (1984): Pre-industrial Population Change. The Mortality Decline and Short-Term Population Movements, Estocolmo, Almquist and Wicksell International.

Biraben, J. N., y Henry, L. (1958): «Les jeunes enfants dans les pays méditerranéens», en Population, núm. 1, pp. 615-644.

BRESCHI, M., y LIV BACCI, M. (1986): «Saison et climat comme contraintes de la survie des enfants. L'expérience italienne au xixème siècle», en Population, $\mathrm{XLI}(1)$, pp. 9-36.

CIPOLLA, C. M. (1993): Contra un enemigo mortal e invisible, Barcelona, Editorial Crítica.

Coale, A. J., y Demeny, P. (1983, 2. ${ }^{a}$ ed.): Regional Model Life Tables and Stable Populations, New York, Academic Press.

Cusso, X. (2000): Alimentació, mortalitat $i$ desenvolupament. Evolució $i$ disparitats regionals a Espanya des de 1860 , tesis doctoral.

DePrEZ, P. (1979): «The Low Countries», en W. R. LEE (ed.), European Demography and Economic Growth, London, Croom Helm Ltd., pp. 236-283.

DeVolder, D. (s. f.): «Tablas de mortalidad provinciales 1976-80», Papers de demografia, núm. 15, Centre d'Estudis Demogràfics (UAB).

DopICO, F. (1987): «Regional Mortality Tables for Spain in the 1860's», en Historical Metbods, vol. 20, núm. 4, pp. 173-179.

DOPICO, F., y REHER, D. S. (1998): El declive de la mortalidad en España, 1860-1930, Asociación de Demografía Histórica, Monografía núm. 1.

Gómez Mendoza, A., y Pérez Moreda, V. (1985): «Estatura y nivel de vida en la España del primer tercio del siglo xx», en Moneda y Crédito, núm. 174, pp. 29-64.

GÓmEz REDONDO, R. (1992): La mortalidad infantil española en el siglo XX, Madrid, CIS-Siglo XXI.

INE (1978): Tablas de mortalidad provinciales (1969-72), Madrid.

Lrvi-BACCI, M. (1978): «La fecundidad y el crecimiento demográfico en España en los siglos XVIII y XIX», en D. V. Glass y R. Revelle (eds.), Población y cambio social. Estudios de demografía histórica, Madrid, Tecnos, pp. 176-187.

- (1988): Ensayo sobre la bistoria demográfica europea. Población y alimentación en Europa, Barcelona, Ariel.

LunN, P. G. (1989): «Nutrition, immunité et infection», en Annales de Démographie Historique, Paris, Societé de Demographie Historique-EHESS.

McKeown, T. (1978): El crecimiento moderno de la pobiación, Barceiona, A. Bosch editor. 
Mosley, W. H., y Chen, L. C. (1984): «Child Survival. Strategies for Research», Supplement to vol. 10, Population and Development Review, Cambridge University Press.

MuNOz PRADAS, F. (1998): «La distribución territorial de la mortalidad infantil en España en torno a 1860: una reconsideración de datos y niveles», Boletín de la Asociación de Demografia Histórica, XVI, núm. II, pp. 187-222.

Nicolau Nos, R. (1989): Trajectoires régionales dans la transition démographique espagnole, Paris, Institut d'Études Politiques de Paris, tesis doctoral.

O'GraDA, C. (1993): «Salud, trabajo y nutrición. Irlanda antes de la hambruna», en Revista de Historia Económica, año XI, núm. 3, pp. 475-502.

Perrenoud, A. (1984): «The mortality decline in a long-term perspective», en J. Bengtsson, G. Fridlizius y R. Ohlsson (eds.), Pre-industrial Population Change. The Mortality Decline and Short-Term Population Movements, Estocolmo, Almquist and Wicksell International, pp. 41-69.

POLLARD, J. H. (1982): «The Expectation of Life and Its Relationship to Mortality», en Journal of the Institute of Actuaries, núm. 109, pp. 225-240.

PReStON, S. (1976): Mortality patterns in national populations. With special reference to recorded causes of death, New York, Academic Press.

Preston, S. H., y Haines, M. R. (1991): Fatal Years. Child Mortality in Late Nineteenth-Century America, Princeton, Princeton University Press.

Reher, D. S.; Pérez-Moreda, V., y Bernabeu-Mestre, J. (1997): «Assessing Change in Historical Contexts: Childhood Mortality Patterns in Spain during the Demographic Transition», en C. A. Corsini y P. P. Viazzo (eds.), The Decline on Infant and Child Mortality. The European Experience: 1750-1990. La Haya, Unicef, Pub. Kluwer Law International.

Salomon-Bayet, C. (1986): Pasteur et la Révolution Pastorienne, Paris, Payot.

SÁEZ, A. (s. f.): La población de Barcelona en 1863 y 1960, Barcelona, Moneda y Crédito.

SÁNCHEZ ALBORNOZ, N. (1975): «La modernización demográfica. La transformación del ciclo vital anual, 1863-1960», en N. SÁNCHEZ ALBORNOZ, Jalones en la modernización de España, Barcelona, Ariel, pp. 147-180.

Sanz Gimeno, A. (1999): La mortalidad de la infancia en Madrid, Madrid, Comunidad de Madrid.

Schofield, R.; Reher, D., y Bideau, A. (eds.) (1991): The Decline of Mortality in Europe, Oxford, Clarendon Press.

Scrimshaw, N. S. (1990): «El valor de los estudios contemporáneos sobre alimentación y nutrición para los historiadores», en R. I. ROTBERG y T. K. RABB (eds.), El hambre en la bistoria, Madrid, Siglo XXI de España Editores, S. A., pp. 365-371.

Wrigley, E. A., y SCHOFIELD, R. (1981): The Population History of England 1541-1871. A Reconstruction, London, Edward Arnold.

Wrigley, E. A. (1993): Cambio, continuidad y azar. Carácter de la Revolución Industrial inglesa, Barcelona, Editorial Crítica. 